NASA/TM-2009-215602

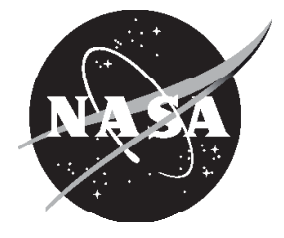

\title{
Fission Surface Power Technology Development Status
}

Donald T. Palac and Lee S. Mason

Glenn Research Center, Cleveland, Ohio

Scott Harlow

U.S. Department of Energy, Germantown, Maryland 


\section{NASA STI Program . . . in Profile}

Since its founding, NASA has been dedicated to the advancement of aeronautics and space science. The NASA Scientific and Technical Information (STI) program plays a key part in helping NASA maintain this important role.

The NASA STI Program operates under the auspices of the Agency Chief Information Officer. It collects, organizes, provides for archiving, and disseminates NASA's STI. The NASA STI program provides access to the NASA Aeronautics and Space Database and its public interface, the NASA Technical Reports Server, thus providing one of the largest collections of aeronautical and space science STI in the world. Results are published in both non-NASA channels and by NASA in the NASA STI Report Series, which includes the following report types:

- TECHNICAL PUBLICATION. Reports of completed research or a major significant phase of research that present the results of NASA programs and include extensive data or theoretical analysis. Includes compilations of significant scientific and technical data and information deemed to be of continuing reference value. NASA counterpart of peer-reviewed formal professional papers but has less stringent limitations on manuscript length and extent of graphic presentations.

- TECHNICAL MEMORANDUM. Scientific and technical findings that are preliminary or of specialized interest, e.g., quick release reports, working papers, and bibliographies that contain minimal annotation. Does not contain extensive analysis.

- CONTRACTOR REPORT. Scientific and technical findings by NASA-sponsored contractors and grantees.

- CONFERENCE PUBLICATION. Collected papers from scientific and technical conferences, symposia, seminars, or other meetings sponsored or cosponsored by NASA.

- SPECIAL PUBLICATION. Scientific, technical, or historical information from NASA programs, projects, and missions, often concerned with subjects having substantial public interest.

- TECHNICAL TRANSLATION. Englishlanguage translations of foreign scientific and technical material pertinent to NASA's mission.

Specialized services also include creating custom thesauri, building customized databases, organizing and publishing research results.

For more information about the NASA STI program, see the following:

- Access the NASA STI program home page at http://www.sti.nasa.gov

- E-mail your question via the Internet to help@ sti.nasa.gov

- Fax your question to the NASA STI Help Desk at 301-621-0134

- Telephone the NASA STI Help Desk at 301-621-0390

- Write to: NASA Center for AeroSpace Information (CASI) 7115 Standard Drive Hanover, MD 21076-1320 
NASA/TM-2009-215602

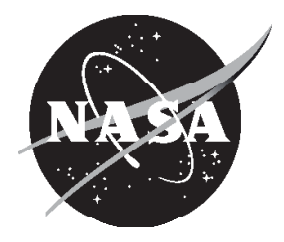

\section{Fission Surface Power Technology Development Status}

Donald T. Palac and Lee S. Mason

Glenn Research Center, Cleveland, Ohio

Scott Harlow

U.S. Department of Energy, Germantown, Maryland

Prepared for the

47th Aerospace Sciences Meeting

sponsored by the American Institute of Aeronautics and Astronautics

Orlando, Florida, January 5-8, 2009

National Aeronautics and

Space Administration

Glenn Research Center

Cleveland, Ohio 44135 


\section{Acknowledgments}

The authors wish to thank Jim Werner of Idaho National Laboratory, Dave Poston of Los Alamos National Laboratory, Lou Qualls of Oak Ridge National Laboratory, and Steve Wright and Ross Radel of Sandia National Laboratories, for their contributions to the FSPS project upon which sections of this paper were based. The information discussed here was compiled for NASA with support from the Exploration Systems Mission Directorate.

Level of Review: This material has been technically reviewed by technical management.

Available from

NASA Center for Aerospace Information 7115 Standard Drive

Hanover, MD 21076-1320
National Technical Information Service 5285 Port Royal Road Springfield, VA 22161

Available electronically at http://gltrs.grc.nasa.gov 


\title{
Fission Surface Power Technology Development Status
}

\author{
Donald T. Palac and Lee S. Mason \\ National Aeronautics and Space Administration \\ Glenn Research Center \\ Cleveland, Ohio 44135 \\ Scott Harlow \\ U.S. Department of Energy \\ Germantown, Maryland 20874
}

\begin{abstract}
With the potential future deployment of a lunar outpost there is expected to be a clear need for a high-power, lunar surface power source to support lunar surface operations independent of the day-night cycle, and Fission Surface Power (FSP) is a very effective solution for power levels above a couple 10's of kWe. FSP is similarly enabling for the poorly illuminated surface of Mars. The power levels/requirements for a lunar outpost option are currently being studied, but it is known that cost is clearly a predominant concern to decision makers. This paper describes the plans of NASA and the DOE to execute an affordable fission surface power system technology development project to demonstrate sufficient technology readiness of an affordable FSP system so viable and costeffective FSP system options will be available when high power lunar surface system choices are expected to be made in the early $2010 \mathrm{~s}$.
\end{abstract}

\section{Nomenclature}

\begin{tabular}{|c|c|}
\hline AFSPSS & Affordable Fission Surface Power System Study \\
\hline ATU & Alternator Test Unit \\
\hline $\mathrm{Cx}$ & Constellation (NASA Vision for Space Exploration flight hardware development program) \\
\hline DOE & Department of Energy \\
\hline ETDP & Exploration Technology Development Program \\
\hline FSP & Fission Surface Power \\
\hline FSPS & Fission Surface Power System \\
\hline FY & Fiscal Year \\
\hline GRC & Glenn Research Center \\
\hline HQ & Headquarters \\
\hline HR & Heat Rejection \\
\hline HRS & Heat Rejection System \\
\hline HX & Heat Exchanger \\
\hline $\mathrm{I} \& \mathrm{C}$ & Instrumentation and Controls \\
\hline INL & Idaho National Laboratory \\
\hline $\mathrm{kg}$ & kilogram \\
\hline $\mathrm{kW}$ & kilowatts \\
\hline $\mathrm{kWe}$ & kilowatts (electric) \\
\hline $\mathrm{kWt}$ & kilowatts (thermal) \\
\hline LaNL & Los Alamos National Laboratory \\
\hline LaRC & Langley Research Center \\
\hline $\begin{array}{l}\text { LAT-II } \\
\mathrm{m}\end{array}$ & $\begin{array}{l}\text { Lunar Architecture Team II } \\
\text { meter }\end{array}$ \\
\hline MSFC & Marshall Space Flight Center \\
\hline $\mathrm{NaK}$ & Sodium/Potassium mixture \\
\hline NASA & National Aeronautics and Space Administration \\
\hline ORNL & Oak Ridge National Laboratory \\
\hline $\mathrm{PC}$ & Power Conversion \\
\hline PMAD & Power Management and Distribution \\
\hline
\end{tabular}




$\begin{array}{ll}\text { RDU } & \text { Radiator Demonstration Unit } \\ \text { rem } & \text { Roentgen Equivalent Man } \\ \text { Rx } & \text { Reactor } \\ \text { SNL } & \text { Sandia National Laboratory } \\ \text { TDU } & \text { Technology Demonstration Unit } \\ \text { TRL } & \text { Technology Readiness Level } \\ \text { yr } & \text { year }\end{array}$

\section{Introduction}

Fission surface power systems (FSPS) have the potential to provide abundant, constant, cost-effective power anywhere on the surface of the Moon or Mars, independent of available sunlight. Safe, efficient, plentiful energy will be one of the keys to meeting NASA's goals for exploration as outlined in the U.S. Space Exploration Policy. This is particularly true for locations where survival for long periods of time in hostile environments will require a constant supply of significant quantities of energy, independent of solar insolation. For such demanding power requirements, nuclear power systems have been shown generally to outperform non-nuclear power systems. To be utilized, however, FSPS must be shown to be performance and cost-competitive with other non-nuclear surface power options, and be designed and made to be launched and used safely.

An important first step in demonstrating the affordability of fission surface power was the completion of the Affordable Fission Surface Power System Study (AFSPSS) in 2007. This study, through rigorous ground-up estimation of the cost of development of a first-unit lunar fission surface power system by a NASA/DOE team with inputs from industry space power system developers, established that the first FSP system could be developed, flight qualified, and delivered for approximately $\$ 1.4$ billion, with subsequent FSPS flight system units costing about \$215 million each. It was also established that this FSP system could be designed to be extensible to Mars surface missions. Consequently, the Exploration Systems Mission Directorate affirmed the continuation of FSPS technology development as a possible power system option for lunar outposts and later exploration missions to Mars. Continuation of the technology program, however, was not a commitment to flight system development; this will depend on the continuing maturation of the lunar surface system architectures, lunar surface power requirements and trade studies of lunar power system options, and refinement of the configuration, risk, and cost of an FSPS based on updated requirements and technology development progress. The relevance of fission surface power to future exploration efforts is highly dependent on the lunar architecture choices and related requirements that have yet to be fully defined for lunar and Mars surface power. However, LAT-II technology recommendations included FSP as a critical technology for minimum capability, and the Constellation Lunar Surface Systems office has indicated that the continuation of FSPS technology development needs to be maintained to enable an informed decision about lunar surface power system architectures and support Lunar Surface Systems reviews in the early 2010s.

The Fission Surface Power Systems Project Team, led by NASA Glenn Research Center (GRC) in partnership with Marshall Space Flight Center (MSFC), Department of Energy (DOE) labs (Oak Ridge National Lab, Idaho National Lab, Los Alamos National Lab, Sandia National Lab), and industrial partners, is conducting a focused FSPS technology development effort. The Exploration Technology Development Program (ETDP) at LaRC provides programmatic oversight of the FSPS Project.

\section{Key Objectives}

The key objective of the FSPS project is to develop and successfully implement project strategies and risk reduction plans (including concept and systems analyses and comparisons along with hardware development and test) so that viable and cost-effective nuclear fission system options will be available when lunar outpost power system decisions are expected to be made in the early 2010s. To this end, the project will:

- Develop an FSPS concept that meets surface power requirements at reasonable cost with added benefits over competitive options

- Establish a hardware-based technical foundation for FSPS design concepts and reduce risk.

- Reduce the cost uncertainties for FSPS and establish greater credibility for flight system cost estimates

- Generate the key gate products that would allow Agency decision-makers to consider FSPS as a viable option to proceed to flight development 
A key theme of this project is that the FSPS concept must be affordable - that is it must be capable of meeting expected surface power requirements at a reasonable cost and be competitive with other surface power options. The Affordable Fission Surface Power System Study concluded that FSP systems could be developed at a reasonable cost to meet NASA's anticipated surface power needs for exploration. Another major output from this study was identification of an "affordable" FSP system development, design, and test approach that was competitive with other non-nuclear lunar outpost power options. As a result, the project adopted an affordable design philosophy for selecting the reference FSPS concept.

The basis of the FSPS affordable design philosophy is founded in principles of conservatism, simplicity, and robustness:

Conservatism:

- Reactor operating temperature is constrained to less than $900 \mathrm{~K}$, a relatively low temperature that allows use of stainless steel and other non-refractory, well-characterized materials for power system structure

- Maximal use of known materials and fluids with demonstrated compatibility with nuclear power applications

- Generous performance and structural margins

- Large safety factors

- Design based on extensive terrestrial reactor power system experience

Simplicity:

- Modest power and lifetime requirements

- Simple controls:

- Negative Temperature Reactivity Feedback: assures safe response to reactor temperature excursions

- Parasitic Load Control: maintains constant power draw regardless of electrical loads and allows thermal system to remain near steady-state

- Slow thermal response

- Conventional design practices

- Established manufacturing methods

- Modular configurations that allow testing of components, subassemblies, and assembled system

Robustness:

- Safe during all mission phases

- High redundancy

- Fault tolerance, including ability to recover from conditions such as:

- Loss of reactor cooling

- $\quad$ Stuck reflector drums

- Power conversion unit failure

- Radiator pump failure

- Loss of radiator coolant

- Loss of electrical load

- High technology readiness level components

- Hardware-rich test program

- Multiple design cycles and hardware iterations

One benefit of the FSPS approach to affordability is inherent safety. In particular, the reactor module will be designed with such a high reflector worth that no credible scenario could cause inadvertent criticality. The FSP system would be designed to be safe during all mission phases. It would be launched cold (with no fission products from nuclear operations) to keep radiation below significant levels. The reactor would be designed to remain subcritical during all postulated mission events prior to startup. During operation, shielding would reduce radiation to safe levels for humans, using either local or earth-delivered materials. External monitoring of the system is not required, even for unusual events. The system is self regulating and responds slowly and stably while adjusting itself to changes. Control actions during the design life of a properly designed FSPS are limited to approximately monthly adjustments of control drum positions to restore the reactor to its design operating temperature as fuel is depleted. Loss of control will result in graceful degradation of power over a period approaching the planned system life until 
the reactor cannot provide sufficient temperature to operate the power conversion units, and the reactor shuts itself down. Radiation levels around the system after shutdown will drop below background levels within days.

Another result of an affordable approach to an FSPS is the identification of the minimum required testing to verify system performance and safety. By staying within the experience base of terrestrial and space reactors, much material and component qualification testing is avoided. Simplicity of the reactor design gives confidence that the system will operate as expected based on prior similar experience. Designing the system for simple, low cost testing enhances early availability of information required for design validation. System simplicity also allows an integrated approach to non-nuclear and nuclear testing such that the amount of nuclear testing, especially at the system level, can be minimized while still providing validation of system performance, operating characteristics and safety.

This has led to a key FSPS tenet that the cost of a fission surface power system could be kept low by keeping subsystem and component risks low. Furthermore, the study identified that these low-risk subsystems and components could provide performance that is sufficient to meet NASA's surface power needs. A primary determinant of subsystem and component risk is the reactor outlet temperature. Limiting this temperature to $900 \mathrm{~K}$ avoids the need for high temperature materials, such as refractory metals, in the construction of the reactor and the balance of plant, and also places the system requirements within the range of prior test or operational experience with terrestrial reactor systems, or in some cases, space flight hardware systems.

\section{Technical Approach}

The goals and objectives of the FSPS project require formation of a basis for a decision concerning the potential development of a fission surface power system for lunar exploration. This requires knowledge of (1) the characteristics, performance, cost, and risks of the system and (2) a foundation in test data for assuring that the key questions involved in a decision to build a fission surface power system are answered with a basis in data. This leads to a highly coupled concept definition and technical risk reduction effort where the products are iterative and staggered so the results in one area can influence the other. Concept Definition activities increase the design fidelity of the FSPS concept, set a baseline for understanding technological challenges (and defining the test-based risk reduction activities needed), quantify the performance of the system, form the basis for cost estimation, and include performance of trade studies that refine the concept as knowledge is gained through analysis and test. The fidelity of the FSPS concept is expected to progress from a preliminary reference concept initially to a recommended lunar outpost FSPS design concept at project completion. Risk reduction activities reduce the technical risk of development of an FSPS, set a foundation in experimental data for answers to key performance, characteristics, cost, and risk questions raised by a decision to develop an FSPS, and provide test hardware that can be applicable to the flight engineering development activity.

A key theme of this approach is the building of knowledge of FSP systems and subsystems through concept development and analysis, with a foundation in hardware development through risk reduction and test. While the development of this hardware-based knowledge base necessarily starts at the component level, component technology development will build the basis subsystem technology hardware demonstrations, culminating in a fullscale non-nuclear Technology Demonstration Unit (TDU). This TDU will provide key information, relevant to a decision to commit to flight development of a lunar outpost FSPS, concerning:

- The characteristics and performance of an integrated FSPS with a simulated reactor heat source,

- The characteristics and performance of critical subsystems, components, and subcomponents of FSPS as they operate within an FSPS.

\section{FSPS Expected Requirements}

In order to demonstrate FSPS technology readiness to the appropriate level by the early 2010's, FSPS technology development must be initiated in advance of complete definition of lunar surface systems requirements. Fortunately, one of the major benefits of a fission surface power system is accommodation of a broad range of planetary surface mission and environment variations by a single system design. This simplifies the definition of a set of expected requirements, since expected mission and environmental variations have been characterized by prior exploration architecture studies, based on and supplemented by data from robotic spacecraft and the Apollo missions. 
Key expected requirements for the FSPS project are:

- The FSPS shall be designed to produce no less than $40 \mathrm{kWe}$ net power output (after accounting for all power losses and auxiliary loads).

- The FSPS shall be designed for use at any location on the lunar surface. Radiator sizing shall be based on worst case surface temperatures and sun angles.

- The FSPS shall be designed to operate for no less than 8 years at full power.

- The FSPS shall be flight-ready for an initial launch and deployment no later than 2020.

- The FSPS shall be designed to produce no less than 50 percent power output after the first credible component failure.

- The FSPS shall be recoverable from all credible operational upsets and transients without adverse safety consequences to the crew or outpost.

- The radiation from the FSPS shall be less than $5 \mathrm{rem} / \mathrm{yr}$ to an unshielded crew member at a $100 \mathrm{~m}$ separation distance. (Assume reactor is installed in pre-excavated hole with upper plug shielding as needed to protect FSPS components and minimize scattered radiation.)

- The reactor shall remain sub-critical during all planned and credible un-planned mission events prior to FSPS startup.

- At its end-of-life, the reactor shall be abandoned in place in a safe shutdown condition.

- The FSPS mass shall be minimized and no greater than the current cargo lander down-mass capability of $14000 \mathrm{~kg}$.

- The FSPS design shall be extensible to the Mars surface. All materials and design strategies shall be compatible with the Martian environment.

\section{FSPS Technology Development Project Structure}

The primary challenge in fielding a FSPS is at the system level. For the purposes of the FSPS project, an FSPS is defined by the architecture shown in Figure 1. While component and subsystems challenges also exist, the definition of a fission surface power system, its demonstration in a flight-like environment, and verification of its performance, risk, and cost for mission requirements are generally at a lower maturity than FSPS component and subsystem technologies. As a result, the maturation of the system technology level is central to the FSPS project.

\section{A. FSPS System Technology Development}

Development of FSP system technology includes concept definition and risk reduction. Concept definition includes design studies on reactor, shield, power conversion, heat rejection, and PMAD to define baseline and options and to integrate results to formulate an overall lunar outpost FSPS design concept. The initial phase of this effort, the selection of a FSPS preliminary reference concept was completed in mid-2008. It included the study of concepts and systems that fed into the selection process, and led to the preliminary reference FSPS concept shown in Figure 2. The concept would deliver $40 \mathrm{kWe}$ to users on the surface of the Moon or Mars. The design life is 8 years. With the reactor emplaced below the surface in a pre-excavated hole, the surface material would provide radiation shielding augmentation, reducing dose at $100 \mathrm{~m}$ to less than $5 \mathrm{rem} / \mathrm{year}$ (an alternative version of this concept with more internal shielding was developed for applications where excavation is precluded). Concept design choices, including low operating temperatures, liquid metal (NaK) working fluid for heat transfer from the reactor to the

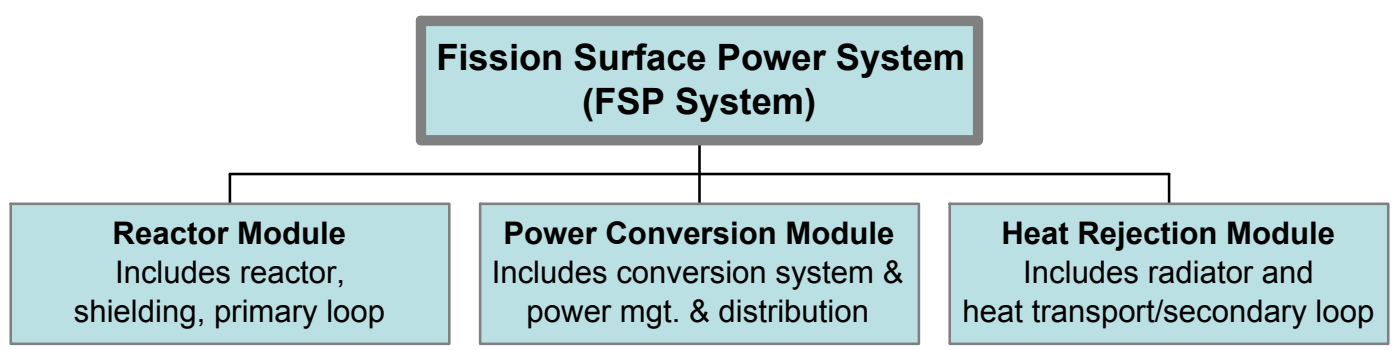

Figure 1.-FSPS Technology Development Project Structure. 


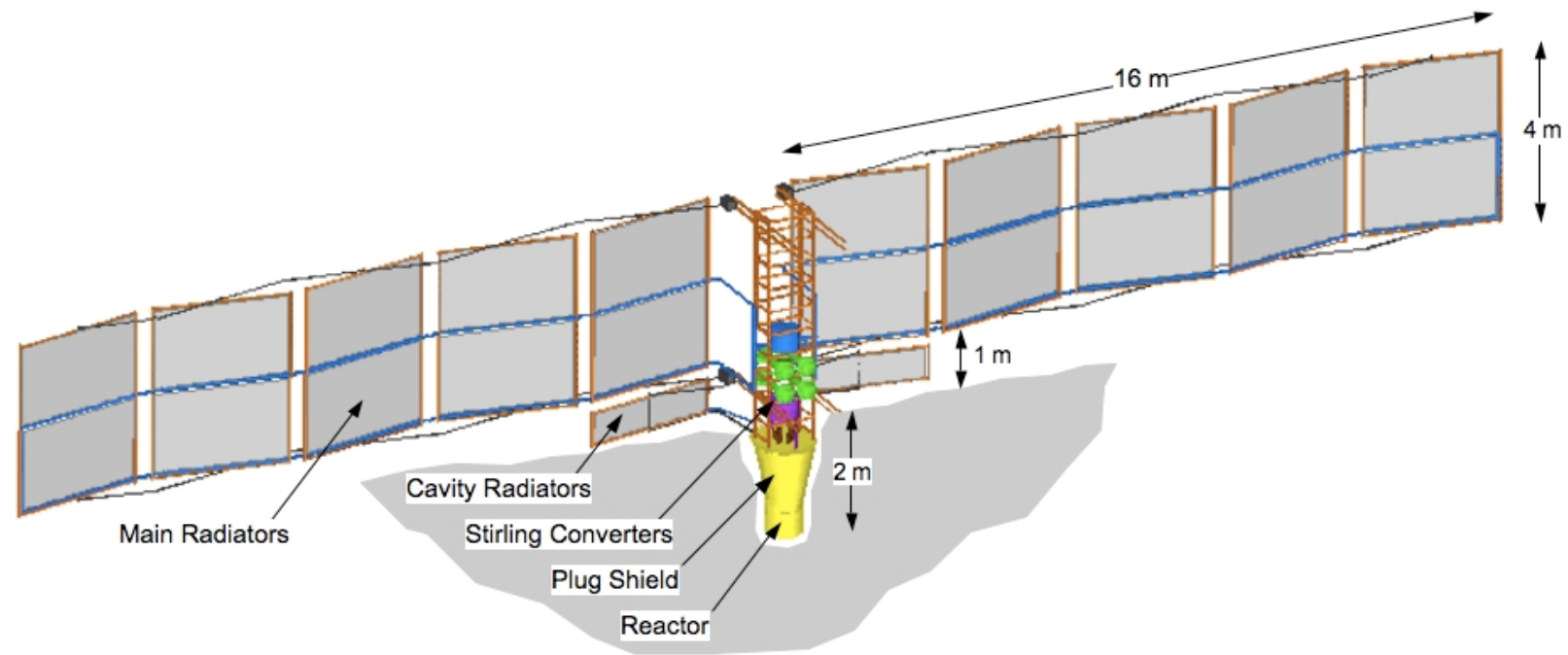

Figure 2.-Affordable Fission Surface Power Preliminary Reference Concept.

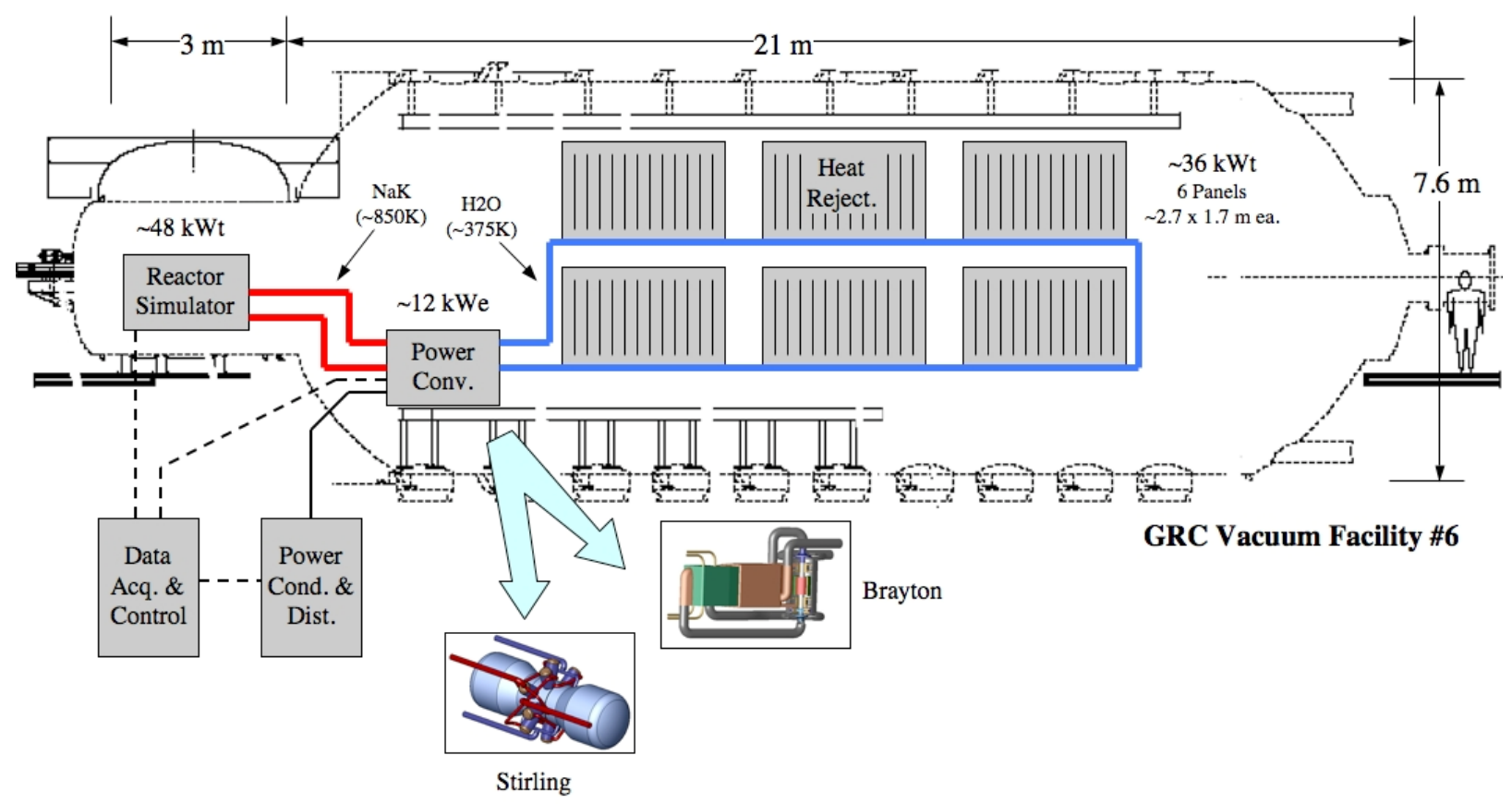

Figure 3.-Technology Demonstration Unit Notional Layout.

power conversion system, uranium oxide reactor fuel with decades of operational experience, and stainless steel construction, all result from the high priority of minimizing cost and development/operations risks.

This reference FSPS concept will serve as the basis for the project's ongoing technology development and demonstration efforts and also help guide technology investment in subsequent years. Concept definition also includes the development of models and tools to accurately predict the performance of an FSP system. System models will be validated by FSPS risk reduction activities, and along with the preliminary reference FSPS concept, will be used to support lunar surface system requirements definition and planning.

FSPS risk reduction consists of the gradual development, buildup, and testing of a system-level Technology Demonstration Unit (TDU) as shown in Figure 3. Component modules, themselves the subject of finer-grained risk reduction development and testing, will be built in such a way as to allow integration into the TDU. Key objectives of the TDU include validation and refinement of FPS requirements, characterization of system-level performance, physical and electrical characteristics, cost and risk. 


\section{B. FSPS Reactor Module Technology Development}

An important outcome of the Affordable Fission Surface Power System Study is that cost of the total FSP system is highly sensitive to the technological complexity and risk of the reactor module. A resultant guideline for the FSPS technology development project is reduction of the technology challenges for the reactor module. FSPS concept definition and trade studies that were conducted in 2007 to 2008 identified candidate reactor subsystems and evaluated their suitability for the fission surface power system application. After much deliberation, the reactor technology selected for this research and development effort was a fast spectrum, liquid metal reactor, cooled with $\mathrm{NaK}$ or possibly $\mathrm{Na}$. The core internals and pressure vessel will largely consist of stainless steel alloy. The operating temperature of the reactor is an important feature in the reactor design and was kept sufficiently low throughout all operating conditions such that high temperatures would not threaten the reliability of reactor components. Operating temperatures will be limited to those at which sufficient data currently exists to provide high confidence in success.

This reactor technology offers the flexibility of interfacing cleanly with the power conversion subsystems under consideration by NASA for the FSPS application. This reactor technology also represents relatively low technology risk and can be easily demonstrated with minimal technology development effort. Since many such reactors have been built in the past and their operational experience has created a significant database, there is confidence that this type of design could be built and operated successfully. The proposed reactor core technology will draw heavily on experience from existing fast reactor designs such as Experimental Breeder Reactor (EBR) II or the Fast Flux Test Facility (FFTF). The objective is to avoid having to go through an expensive fuel and reactor technology qualification effort, and instead, rely on the existing experience on these types of fuel elements and reactor cores. The actual fuel forms to be considered will be limited to oxide.

Three areas of planetary surface reactor subsystems risk were identified as critical and in need of early focus (1) the primary heat transfer loop (which connects the reactor to the power conversion system), (2) shielding, and (3) instrumentation and controls. The thermal-hydraulics of the reactor module will require technology assessment and development, including candidate electromagnetic pumps, heat exchangers, and other heat transfer subsystem components.

Reactor shielding for an FSPS will rely extensively on terrestrial shield technology experience. While FSP requirements do not pose significant challenges to shield design and development, the shield is likely to represent the single highest mass component of the FSPS. Low-risk technology options to minimize shield mass while maintaining adequate margin on radiation control will be evaluated.

In a similar fashion, the design of the reflector will need to take into account its reliability over the design lifetime. Long-life reactivity control mechanisms and reactor control subsystems and electronics that are radiationresistant and capable of operating without human interaction will be evaluated. Also, because of the long, unattended operating cycle, the alternatives to equip the reactor control subsystem with sensors, electronics, and embedded logic to automatically adjust the reactor to operating changes will be evaluated.

Technologies for testing of reactor interactions with the balance of plant subsystems may also need to be developed to allow the NASA/DOE team to gain assurance that the FSPS concept is viable and to measure FSP system performance.

In response to these challenges, the FSPS reactor module technology development objectives are to:

- Conduct design studies and experimental testing on reactor component technologies that are applicable to the reference FSP system

- Define the reactor fuel type and qualification process

- Develop prototypic test articles and evaluate performance (e.g., reflector drives, instrumentation, shielding materials, fuel pin simulators)

- Characterize reactor interfaces and evaluate interactions across reactor module interfaces

- Evaluate radiation environment effects on material properties and component life

- Provide realistic test environment for evaluation of primary loop components and behavioral phenomenon

- Accurately simulate the heat transfer and fluid flow conditions expected in the primary loop

- Develop prototypic test articles and evaluate performance (e.g., pumps, heat exchangers, sensors)

- Characterize primary loop interfaces and evaluate interactions with mating components

- Establish safe and reliable liquid metal handling procedures

\section{FSPS Power Conversion Module Technology Development}

The objective of Power Conversion module technology development is to develop test plans and conduct testing on power conversion systems, PMAD, and related materials. The primary focus is on Brayton and Stirling power 
conversion systems. Near term plans are to assemble and test sub-scale systems to serve as "Pathfinders" for future development units. The Pathfinder units will be integrated with representative heat source simulators under development by MSFC and DOE. This task will leverage existing equipment currently available at GRC including the $2 \mathrm{~kW}$ Brayton, $30 \mathrm{~kW}$ dual-Capstone Brayton, $2 \mathrm{~kW}$ Stirling, $50 \mathrm{~kW}$ Alternator Test Unit (ATU), and lunar PMAD testbed. The activities will focus on reducing development risk in several key areas including heat source integration, electrical integration, materials integration, component performance, transient operations, and autonomous controls.

Upon selection of the power conversion strategy for a notional Mars-extensible lunar surface power system, work will begin on development of a $12 \mathrm{kWe}$ power conversion demonstrator unit that will serve as the core of the FSPS TDU (see Figure 3). A $12 \mathrm{kWe}$ target provides a modular power conversion unit size that can be combined into planetary surface power systems with redundancy at expected required power levels (e.g., two units for a $24 \mathrm{kWe}$ capability; four for a $48 \mathrm{kWe}$ capability). Leading candidates at present are Stirling and Brayton cycle systems. Current trades, along with availability of future funding, will determine whether a single option will be developed, or whether a backup will be carried to some state of readiness. During this development, data from subscale power conversion system testing, materials testing, and alternator/PMAD testing will be used to update and validate FSPS component and system models. The integrated data will be used to support updates to the FSPS concept, including performance, mass, configuration, and cost information, and supplied as required to Constellation lunar surface systems planning activities.

\section{FSPS Heat Rejection Module Technology Development}

The objective of Heat Rejection module technology development is to develop test plans and conduct testing on radiator components and related materials for use in heat rejection systems for Brayton- and Stirling-based power conversion systems. The work will include tests of a Radiator Demonstration Unit (RDU) and titanium-water heat pipes, and use the knowledge gained from these efforts to provide data to validate FSPS models and to refine the FSPS concept. Polymer Matrix Composite (PMC) materials will be assembled into test coupons and full scale radiator panels to validate their long term thermal/structural performance as well as the analytic design tools and methodologies. Development of a $6 \mathrm{kWt}$ "Pathfinder" RDU will be accomplished in FY09.

The $6 \mathrm{kWt}$ Pathfinder RDU will provide data to resolve the selection of heat transport approach, heat pipe configuration, radiator panel configuration, and radiator materials and coatings strategies sufficient to begin design and fabrication of a larger heat rejection subsystem for the TDU. The heat rejection assembly including heat transport loop and radiator panels will be integrated with the other TDU components and tested in a relevant environment to provide full-system-fidelity non-nuclear TRL 6 validation.

\section{FSPS Technology Development Project Plan Summary}

Figure 4 shows a time-phased summary of the integrated FSPS technology development plan. The figure reflects the parallel nature of the concept definition and hardware-based risk reduction elements of the project.

The role of concept definition in providing guidance to the risk reduction activity is demonstrated as FY09 initial FSPS concept definition forms the framework for development of power conversion, heat rejection, and system TDU test hardware configurations. Concept definition also supports Constellation Lunar Surface Systems (Cx LSS) studies, planning and requirements development, which in turn can influence consequent FSPS technology development activity. In addition, FSPS models, supported by tool development, provide the analytic basis for system and subsystem trade studies and concept refinements, and are benchmarked via hardware performance testing.

The progression of risk reduction activities from subsystem pathfinder tests to the non-nuclear full-scale quarterpower system TDU is shown in the lower part of Figure 4. Reactor module (primary test circuit plus reactor component and radiation testing activities) support definition of the reactor module configuration, as well as the development of the non-nuclear reactor simulator which will be used in a flight-like environment as the heat source portion of the TDU. Power conversion and heat rejection pathfinder testing are forming the basis for definition of the reference concept baseline, which will in turn guide the configuration of the full-scale test units. These test units will serve the purpose first of validating subsystem performance, and providing a basis in hardware testing for $\mathrm{Cx}$ LSS detailed requirements definition and future reviews. They will subsequently be integrated into the full-scale system TDU to provide the first non-nuclear demonstration of a fission surface power system in a flight-like environment. 


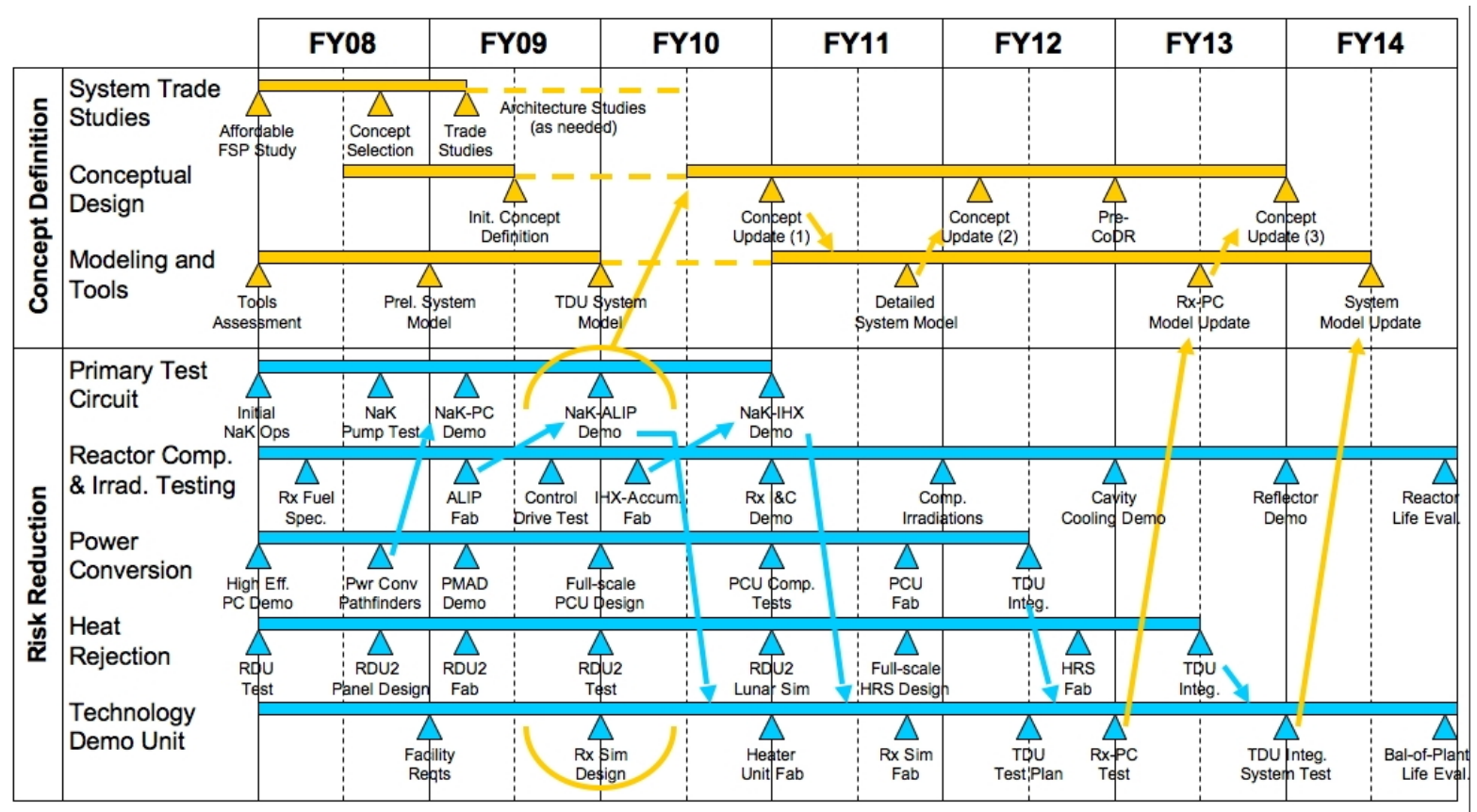

Figure 4.-FSPS Technology Development Plan Summary.

\section{References}

Mason, L.S., A Comparison of Fission Power System Options for Lunar and Mars Surface Applications, NASA/TM-2006-214120, February, 2006.

Mason, L.S., A Practical Approach to Starting Fission Surface Power Development, NASA/TM-2006-214366, July, 2006.

Mason, L.S., Poston, D., and Qualls, L., System Concepts for Affordable Fission Surface Power, NASA/TM2008-215166, January, 2008. 


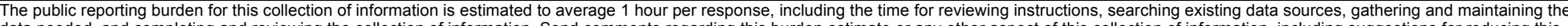

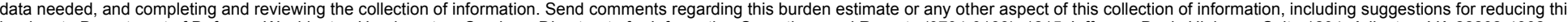

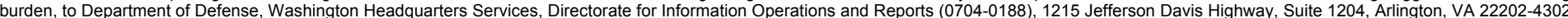

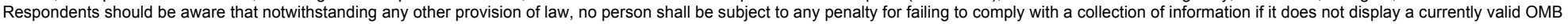
control number.

PLEASE DO NOT RETURN YOUR FORM TO THE ABOVE ADDRESS.
1. REPORT DATE $(D D-M M-Y Y Y Y)$
2. REPORT TYPE
3. DATES COVERED (From - To)

01-03-2009

Technical Memorandum

\section{TITLE AND SUBTITLE}

Fission Surface Power Technology Development Status

5a. CONTRACT NUMBER

5b. GRANT NUMBER

5c. PROGRAM ELEMENT NUMBER

6. AUTHOR(S)

Palac, Donald, T.; Mason, Lee, S.; Harlow, Scott

\section{5d. PROJECT NUMBER}

5e. TASK NUMBER

5f. WORK UNIT NUMBER

WBS 463169.01.03.01.01

8. PERFORMING ORGANIZATION

REPORT NUMBER

E-16892

National Aeronautics and Space Administration

John H. Glenn Research Center at Lewis Field

Cleveland, Ohio 44135-3191

9. SPONSORING/MONITORING AGENCY NAME(S) AND ADDRESS(ES)

National Aeronautics and Space Administration

Washington, DC 20546-0001

10. SPONSORING/MONITORS
ACRONYM(S)
NASA; AIAA
11. SPONSORING/MONITORING
REPORT NUMBER
NASA/TM-2009-215602; AIAA-2008-
7812

\section{DISTRIBUTION/AVAILABILITY STATEMENT}

Unclassified-Unlimited

Subject Category: 20

Available electronically at http://gltrs.grc.nasa.gov

This publication is available from the NASA Center for AeroSpace Information, 301-621-0390

\section{SUPPLEMENTARY NOTES}

\section{ABSTRACT}

With the potential future deployment of a lunar outpost there is expected to be a clear need for a high-power, lunar surface power source to support lunar surface operations independent of the day-night cycle, and Fission Surface Power (FSP) is a very effective solution for power levels above a couple 10's of kWe. FSP is similarly enabling for the poorly illuminated surface of Mars. The power levels/requirements for a lunar outpost option are currently being studied, but it is known that cost is clearly a predominant concern to decision makers. This paper describes the plans of NASA and the DOE to execute an affordable fission surface power system technology development project to demonstrate sufficient technology readiness of an affordable FSP system so viable and cost-effective FSP system options will be available when high power lunar surface system choices are expected to be made in the early $2010 \mathrm{~s}$.

\section{SUBJECT TERMS}

Nuclear power

16. SECURITY CLASSIFICATION OF:

a. REPORT

$\mathrm{U}$

b. ABSTRACT
U

U

\section{LIMITATION OF} ABSTRACT

UU

18. NUMBER
OF
PAGES
15

PAGE

$\mathrm{U}$ 19a. NAME OF RESPONSIBLE PERSON

STI Help Desk (email:help@sti.nasa.gov)

19b. TELEPHONE NUMBER (include area code) 301-621-0390 

